\title{
Instability Mode and Movement Characteristics of Dangerous Rock Body in Steep Rock Slope
}

\author{
Junguang HUANG ${ }^{\text {a,b,1 }}$, Shuai ZHANG ${ }^{\text {a,b }}$, Lei LI ${ }^{\mathrm{a}, \mathrm{b}, \mathrm{c}}$ and Weike LI ${ }^{\mathrm{a}, \mathrm{b}}$ \\ ${ }^{a}$ Guangzhou Design Institute Group Co., Ltd, Guangzhou, 510620, China \\ ${ }^{\mathrm{b}}$ Guangzhou Construction Group Co., Ltd, Guangzhou, 5100030, China \\ ${ }^{\mathrm{c}}$ School of Civil Engineering, Guangzhou University, Guangzhou 510006, China
}

\begin{abstract}
The cutting relationship and development degree of structural plane control the instability mode and scale of rock slope. The trajectory of rock mass after instability is an important basis for the design of dangerous rock prevention. The back slope of a residential area was investigated in this paper. Based on the survey data of the field structure surfaces, the possible instability mode of the slope rock mass was analyzed by using the stereographic projection method. The shear strength parameters of the rock mass were inverted through the investigation of dangerous rock mass. Finally, ANSYS/LS-DYNA was used to simulate the dangerous rock mass motion trajectory. This study provides a reference for the analysis of the instability process of single rock.
\end{abstract}

Keywords. Dangerous rock mass, instability mode, parameter inversion, motion trajectory

\section{Introduction}

Dangerous rock is a common type of geological disaster in nature, which refers to the rock mass with poor stability formed by the combination of multiple groups of rock mass discontinuities on the high and steep slope. Dangerous rock is easy to lose stability and move to form collapse under external induced factors [1]. The scale of dangerous rock is uneven, and its volume varies from several cubic meters to hundreds of cubic meters. The occurrence of dangerous rock is gradual and sudden, which often brings irreparable losses to human production and life. Many scholars have studied the formation conditions, instability mode, and movement characteristics of dangerous rock mass. For example, Arefmo et al. investigated the geological disaster of dangerous rock and rockfall in Yemen, and analyzed the inducing factors of dangerous rock and rockfall, such as rock fracture, vegetation and human activities [2]. Fu and Deng used stereographic projection method to analyze the stability of dangerous rock mass, and then combined with rigid body limit equilibrium method for quantitative calculation [3]. $\mathrm{Hu}$ divided the slop failure into five basic forms, such as dumping, sliding and pulling fracture based on the instability mode of dangerous rock body [4]; Liu studied the deformation and failure modes of different dangerous rock mass by using a numerical

\footnotetext{
${ }^{1}$ Junguang Huang, Guangzhou Design Institute Group Co., Ltd, Guangzhou, 510620, China; E-mail: huangjunguang@gzdi.com.
} 
software DDA [5]; Ye simulated the process of dangerous rock mass from instability to final movement stop under various factors by using discrete element software UDEC, and obtained the displacement and strain fields at different stages of dangerous rock body [6]. Researches were also made on wedge failure of rock slope. For example, Wang and Xue carried out the dynamic analysis of the wedge, derived the dynamic balance formula of the wedge, and established the mechanical theoretical basis of the wedge sliding [7]. Tao et al. discussed the stability of wedge under earthquake, and gave the calculation formula of dynamic safety factor of wedge in horizontal and vertical direction under earthquake force [8]. Ma et al. extracted the geometry of the wedge from the three-dimensional structural plane digital model, and analyzed and calculated the stability system [9]. As a summary, a large number of researches have provided theoretical basis for the prevention and control of dangerous rock. However, slope stability analysis is a complex engineering mechanics problem. The deformation failure modes in different areas are difficult to be quantified uniformly. Moreover, there is no comprehensive research on the track characteristics of wedge deformation and failure.

In this paper, a dangerous rock mass in the actual project is investigated. The instability deformation mode of slope rock mass is analyzed, and the movement process of dangerous rock mass is simulated by nonlinear dynamic finite element ANSYS/LS-DYNA software, which truly reflects the movement characteristics of dangerous rock mass in three-dimensional space. This study is able to provide reference value for accurately judging the instability trend of dangerous rock mass.

\section{Engineering Project}

Figure 1 shows the landscape of the study area. Two geomorphic units exist in the area of a small area, namely, the low mountain residual hills and the inter mountain depressions. The northern and eastern parts of the area are denuded low mountain residual hills, the central and southern parts are intermountain depressions, and the west and south areas of the research area are the front alluvial plain. The terrain is generally high in the north, low in the south and low in the east and low in the west. The highest point of the low mountain residual hills is located at the top of the eastern peak with an elevation of $286.9 \mathrm{~m}$, the lowest point is located in the concave between the mountains in the southwest, with an elevation of $33.5 \mathrm{~m}$, a relative elevation difference of $253.4 \mathrm{~m}$ and a terrain slope of $5^{\circ} \sim 30^{\circ}$. The area is mostly covered by dense forest. The concave terrain between the middle and south is relatively flat, with the ground elevation of $33.5 \mathrm{~m} \sim 50.5 \mathrm{~m}$ and the relative height difference of $17.0 \mathrm{~m}$.

The surface of the site receives sufficient solar radiation, and is affected by the monsoon since it is located in low latitude. In summer, the ocean warm air flow forms a high temperature, high humidity and rainy climate; in winter, the northern continental cold wind forms a low temperature, dry and less rainy climate. The annual rainfall is $1623.6 \mathrm{~mm} \sim 1899.8 \mathrm{~mm}$, the annual maximum rainfall is $2678.9 \mathrm{~mm}$, the daily maximum rainfall is $284.9 \mathrm{~mm}$, and the hourly maximum rainfall is $82.4 \mathrm{~mm}$. No surface river exists in the study area except a small number of springs distributed in the low mountains and residual hills. 


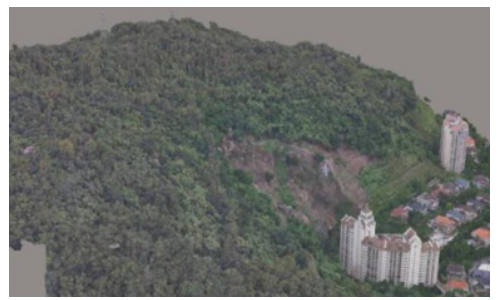

Figure 1. Landscape of the study area.

The outcropping lithology in the area is mainly porphyritic biotite monzogranite in the first stage $\left(\eta \gamma_{5}^{3-1}\right)$ of late Yanshanian period and fine-grained biotite granite in the third stage $\left(\gamma_{5}^{3-1}\right)$. The first stage of late Yanshanian period is widely distributed, and the later stage of the third period is intruded, which is generally distributed in a NE belt. The surface of the slope is covered with quaternary eluvium (Qel+dl), mainly composed of sandy clay formed by weathering and residual of granite and migmatite, and a small amount of gravelly clay with slightly weathered granite, with a thickness of $1.30 \mathrm{~m} \sim 11.20 \mathrm{~m}$.

The study area is located in the central part of the fold bundle of the South China paraplatform and Xiang-Gui-Gan-Yue skinfold system, and in the southwest of Zengcheng uplift. The closest faults are the Wenchong fault and Shougouling Luofushan fault located around $4 \mathrm{~km} \sim 8 \mathrm{~km}$ in the south of the study area. According to the seismic design codes of China GB/T 17742-2008 and GB18306-2015, the basic seismic intensity of the study area is VI and the design seismic acceleration is $0.10 \mathrm{~g}$.

Before the construction of the residential area, the site was a mining area, forming a large number of artificially excavated high and steep slopes. The residential area was planned close to the high and steep rocky high slope. The high and steep slope with a height difference of about $80 \mathrm{~m}$ at the wedge development site is composed of granite, block structure and good integrity. The surface layer of the slope top is covered with 3 m-5 m thick eluvial soil layer.

\section{Failure Mode Analysis of Rock Slope}

According to the field investigation, the slope is composed of massive granite, the structural plane of the slope is not developed, the integrity is good, and the overall stability is high. However, a small number of structural planes are developed locally, and under the cutting action of unfavorable structural planes, dangerous rock may fall locally.

According to the field investigation, the slope is mainly cut by two groups of structural planes, the occurrence of which are respectively $\mathrm{J} 1: 286^{\circ} \angle 43^{\circ}$ and $\mathrm{J} 2$ : $164^{\circ} \angle 55^{\circ}$ where the slope inclination is $250^{\circ}$ and the slope angle is $50^{\circ}$. Figure 2 shows the stereographic projection method for analyzing the formation mode of the collapse. It is found that the occurrence of intersection line between slope and $\mathrm{J} 1$ is $290^{\circ} \angle 43^{\circ}$, the occurrence of intersection line between slope and $\mathrm{J} 2$ is $213^{\circ} \angle 44^{\circ}$ and the occurrence of intersection line between $\mathrm{J} 1$ and $\mathrm{J} 2$ is $232^{\circ} \angle 28^{\circ}$. Under the cutting action of the two groups of structural planes, it is very likely to produce the wedge sliding instability mode. 


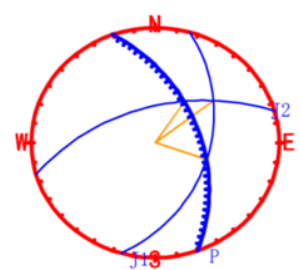

Figure 2. Stereographic projection of wedge.

After the rainstorm on the evening of June 8th, 2018, a collapse occurred on the back slope of the high-rise building in the residential area, which led to the damage of the overhead floor of the first floor of the high-rise building and the reinforced concrete retaining wall between the slope and the high-rise building. The collapse material is from the dangerous rock mass shown in figure 3 . The dangerous rock body is cut by the above two groups of structural surfaces, and wedge sliding occurs under the influence of its gravity and rainfall, jumps in the air after leaving the parent body, and collides with the slope. After reaching the toe of the slope, it collides with the reinforced concrete wall and the overhead layer of the high-rise building. The strong impact force results in serious damage in the retaining wall and the building wall, as shown in figure 4.

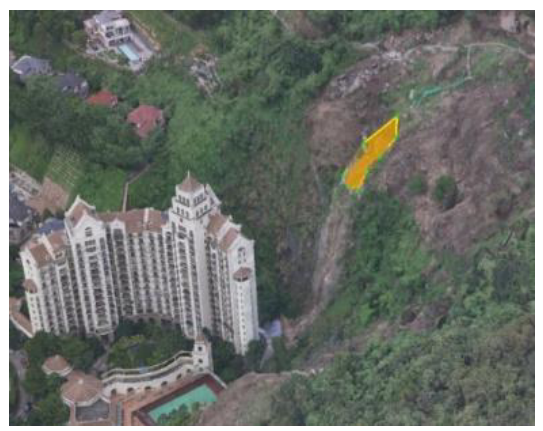

Figure 3. Diagram of wedge sliding.

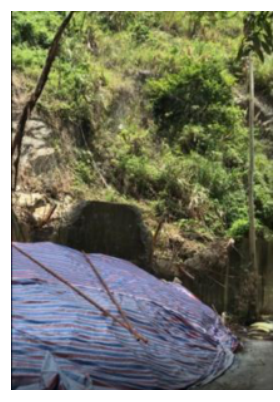

a) Retaining wall

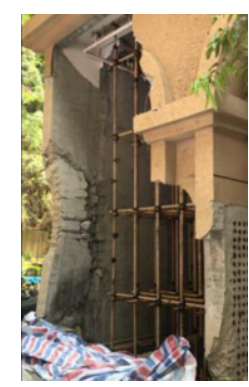

b) Overhead layer of building

Figure 4. Damage caused by collapse. 


\section{Stability Evaluation and Parameter Inversion of Wedge}

The sliding surface of wedge-shaped sliding is composed of two weak structural planes with opposite inclination. The inclination of intersection line is the same as that of slope surface, and the inclination angle is less than that of slope angle.

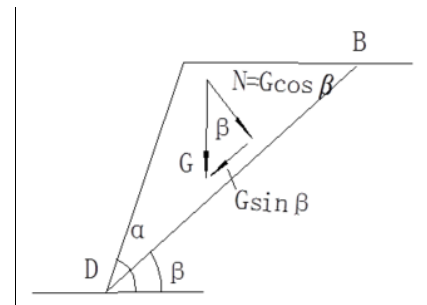

(a)

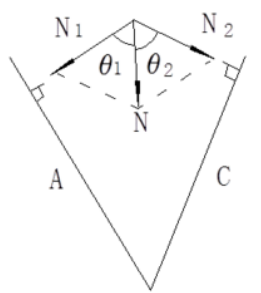

(b)

Figure 5. Schematic diagram of wedge stress analysis.

When calculating the stability of wedge sliding, the self-weight of the sliding body is first decomposed into the component $\mathrm{N}$ of the vertical intersection line $\mathrm{BD}$ and the component of the parallel intersection line (i.e. the sliding force Gsin $\beta$ ). Then $\mathrm{N}$ is projected to the normal direction of the two sliding surfaces, and the normal forces N1 and N2 acting on the sliding surface are obtained. Finally, the anti-sliding force and stability coefficient are obtained.

The sliding force of the possible sliding body is Gsin $\beta$, and the component of the vertical intersection line is $\mathrm{N}=\mathrm{G} \cos \beta$. The normal forces $\mathrm{N} 1$ and $\mathrm{N} 2$ are obtained by projecting Gcos $\beta$ onto the normal direction of $\triangle \mathrm{ABD}$ and $\triangle \mathrm{BCD}$.

The sliding force of the possible sliding body is $G \cos \beta$, and the component of the perpendicular intersection line is $\mathrm{N}=\mathrm{G} \cos \beta . \mathrm{G} \cos \beta$ is projected onto the normal direction of $\triangle \mathrm{ABD}$ and $\triangle \mathrm{BCD}$ planes, and the normal forces $\mathrm{N} 1$ and $\mathrm{N} 2$ are obtained.

$$
\begin{aligned}
& N_{1}=\frac{N \sin \theta_{2}}{\sin \left(\theta_{1}+\theta_{2}\right)}=\frac{G \cos \beta \sin \theta_{2}}{\sin \left(\theta_{1}+\theta_{2}\right)} \\
& N_{2}=\frac{N \sin \theta_{1}}{\sin \left(\theta_{1}+\theta_{2}\right)}=\frac{G \cos \beta \sin \theta_{1}}{\sin \left(\theta_{1}+\theta_{2}\right)} \\
& F_{s}=N_{1} \operatorname{tg} \varphi_{1}+N_{2} \operatorname{tg} \varphi_{2}+C_{1} S_{\triangle A B D}+C_{2} S_{\triangle B C D}
\end{aligned}
$$

The stability factor of the slope can be written as:

$$
\eta=\frac{N_{1} \operatorname{tg} \varphi_{1}+N_{2} \operatorname{tg} \varphi_{2}+C_{1} S_{\triangle A B D}+C_{2} S_{\triangle B C D}}{G \sin \beta}
$$


Figure 5 shows the spatial vector analysis of the structural plane, in which $\alpha=232^{\circ}$ and $\beta=28^{\circ}$. The cosine of the vector can be calculated as follows:

$$
\begin{aligned}
& l=\cos \beta \sin \alpha=-0.37 \\
& m=\cos \beta \sin \alpha=-0.29 \\
& n=\sin \beta=0.88
\end{aligned}
$$
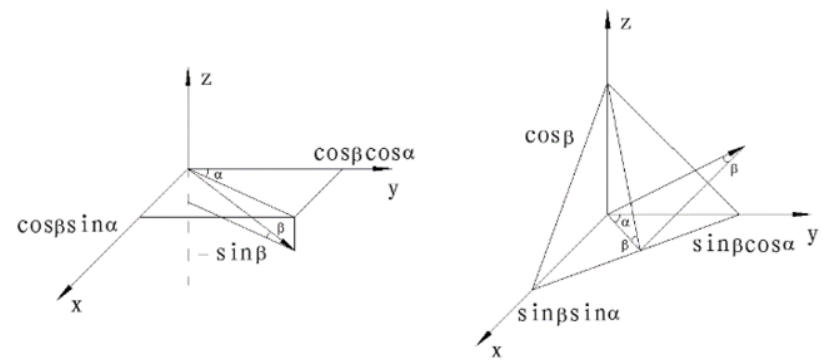

Figure 6. Principle of space vector analysis of structural plane.

The unit normal vectors of the two structural planes $\bar{n}_{1}\left(l_{1}, m_{1}, n_{1}\right)$ and $\bar{n}_{2}\left(l_{2}, m_{2}, n_{2}\right)$ are calculated as follows:

$$
\begin{aligned}
& l_{1}=\cos \left(90^{\circ}-\beta\right) \cdot \sin \alpha=\sin \beta \sin \alpha=-0.65 \\
& m_{1}=\cos \left(90^{\circ}-\beta\right) \cdot \cos \alpha=\sin \beta \cos \alpha=0.18 \\
& n_{1}=\sin \left(90^{\circ}-\beta\right)=\cos \beta=0.74
\end{aligned}
$$

Similarly, $l_{2}=-0.22, m_{2}=0.79, n_{2}=0.57$ can be obtained. The angle between the unit normal vector and the direction vector of $\mathrm{N}$ is transformed into two structural surfaces. The cosine $\left(l_{N}, m_{N}, n_{N}\right)$ of $\mathrm{N}$ can be obtained by the following formula:

$$
l_{N}=-\frac{n}{\sqrt{1-n^{2}}}, \quad m_{N}=-\frac{m \cdot n}{\sqrt{1-n^{2}}}, n_{N}=\sqrt{1-n^{2}}
$$

The cosine of $\theta_{1}$ and $\theta_{2}$ are then calculated as:

$$
\begin{gathered}
\cos \theta_{1}=l_{1} l_{N}+m_{1} m_{N}+n_{1} n_{N} \\
\cos \theta_{2}=l_{2} l_{N}+m_{2} m_{N}+n_{2} n_{N} \\
\theta_{1}=67.33^{\circ}, \theta_{2}=44.40^{\circ} \text { are obtained. }
\end{gathered}
$$


According to Eq. (4), the stability coefficient of wedge can be calculated as 0.95 . The wedge is in an unstable state, which is consistent with the actual situation. The shear strength parameters of the structural plane are inversed by using the rigid body limit equilibrium method. As presented table 1, the choice of the shear strength parameters of the structural plane can be $\mathrm{c}=5 \mathrm{kPa}$ and $\varphi=23^{\circ}$.

Table 1. Sensitivity analysis of wedge stability coefficient.

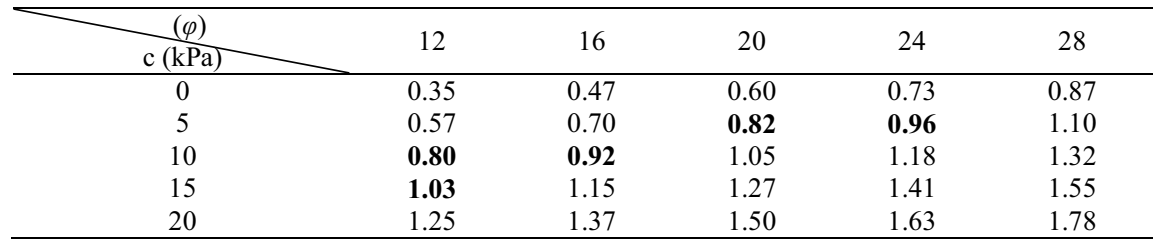

\section{Numerical Simulation of Movement Trajectory of Unstable Dangerous Rock Body}

The prediction of dangerous rock movement trajectory is the main way to determine the jumping height of dangerous rock and the scope of disaster threat, and it is also the basis of collapse protection design. Numerical simulation is one of the research means to predict the dangerous rock movement trajectory. The movement process of dangerous rock is affected by its own geometric characteristics and strength, slope conditions such as slope, slope height, slope undulation and slope material conditions.

ANSYS LS-DYNA is an explicit general nonlinear dynamic analysis finite element program, which can solve the nonlinear problems of various nonlinear structures such as high-speed collision, explosion and metal forming. The transient dynamic problems for solving geometric nonlinearity, material nonlinearity and contact nonlinearity have been widely applied to the simulation analysis of collision and drop problems.

The wedge motion model involves three kinds of materials, namely wedge, rock and soil mass and retaining wall. The parameters of retaining wall and building are set to be the same and are listed in table 2 . The stiffness of the wedge is very large in comparison to that of the wedge, thus the latter can be idealized as a rigid body. Both the rock and soil in the model are elastic-plastic, and the bilinear isotropic model is adopted. The elastic deformation is governed by the elastic model and Poisson's ratio of rock and soil, and the plastic deformation is governed by the yield stress and tangent modulus of rock and soil. The plastic-kinematic model is used for the constitutive model of the reinforced concrete wall. The Cowper Symonds model is selected as the strain rate of the material. Under the impact load, the elastic-plastic stress-strain relationship is not only related to the properties of the material itself, but also related to the time history of loading. According to the parameters of structural plane, the contact friction coefficient between the wedge and the structural plane is 0.42 , and the contact friction coefficient between the wedge and other parts is 0.8. Solid164 element is adopted for modeling dangerous rock. The boundary condition is fixed at the bottom and constrained by four side normal displacement. The numerical simulation only investigates the variation law of each physical quantity in the process of wedge movement. No external load is applied except the self-weight. 
Table 2. Calculation parameter table.

\begin{tabular}{llllll}
\hline Material & $\rho\left(\mathrm{kg} / \mathrm{m}^{3}\right)$ & $\begin{array}{l}\text { Elastic } \\
\text { modulus } \\
(\mathrm{Pa})\end{array}$ & $\begin{array}{l}\text { Poisson's } \\
\text { ratio }\end{array}$ & $\begin{array}{l}\text { Yield stress } \\
(\mathrm{Pa})\end{array}$ & $\begin{array}{l}\text { Tangent } \\
\text { modulus } \\
(\mathrm{Pa})\end{array}$ \\
\hline Rock and soil mass & 1900 & $3.00 \times 10^{7}$ & 0.36 & $4.0 \times 10^{4}$ & $2.15 \times 10^{3}$ \\
Wedge & 2690 & $5.00 \times 10^{10}$ & 0.24 & $/$ & $/$ \\
Retaining wall & 7850 & $2.07 \times 10^{11}$ & 0.22 & $3.1 \times 10^{8}$ & $7.63 \times 10^{8}$ \\
\hline
\end{tabular}

The wedge is controlled by the cutting of two groups of structural planes, and will be damaged under the condition of self-weight and rainfall. The wedge is located at the elevation of $160 \mathrm{~m}$ of high slope. The $\mathrm{Z}$-axis is defined as the upward direction of the wedge, the Y-axis is defined as the direction of the high slope trend, and the $\mathrm{X}$-axis is defined as the direction of the high slope tendency. Figure 6 shows the finite element mesh of the study area.

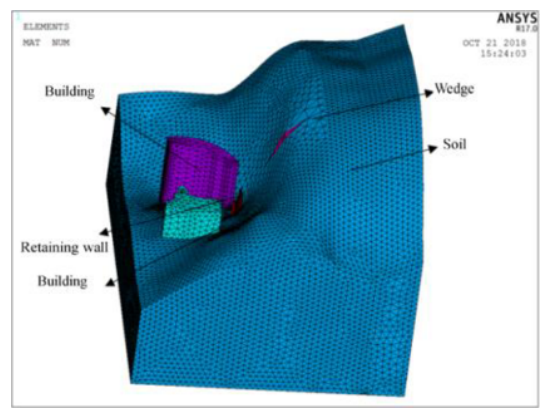

Figure 7. Finite element mesh of the study area.

Figure 7 shows the numerical simulation results. The red wedge represents the initial position of the wedge, and the yellow wedge represents its resting position. The results indicate that the wedge slides down and falls under the action of self-weight after instability, and will finally stops colliding with the retaining wall.

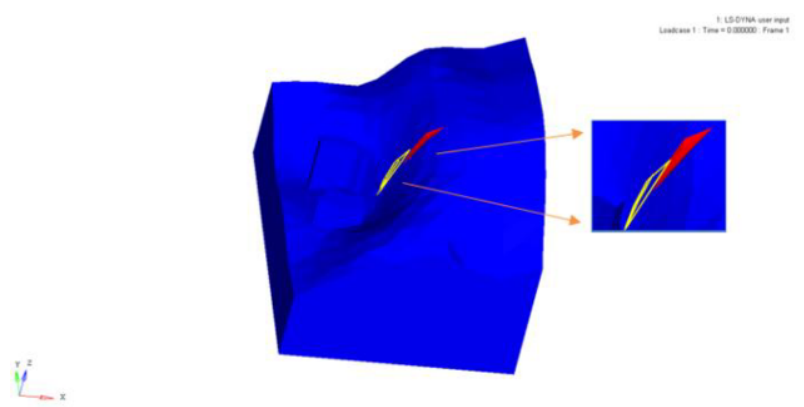

Figure 8. Wedge motion history diagram.

The displacements of wedge in the $\mathrm{X}, \mathrm{Y}$ and $\mathrm{Z}$ directions during the movement are set and presented in table 3, among which the maximum falling distance is $105 \mathrm{~m}$, the maximum migration distance is $68 \mathrm{~m}$, and the maximum offset distance is $10 \mathrm{~m}$. 
Table 3. Displacement of wedge motion.

\begin{tabular}{llllllllll}
\hline Time & 0 & 1 & 2 & 3 & 4 & 5 & 6 & 7 & 8 \\
\hline $\mathrm{X}$ & 0 & 1.9 & 5 & 10 & 19 & 30 & 45 & 61 & 68 \\
$\mathrm{Y}$ & 0 & 0 & 0 & 2 & 3.5 & 5.8 & 8 & 10 & 10 \\
$\mathrm{Z}$ & 0 & 6 & 10 & 19 & 32 & 50 & 71 & 97 & 105 \\
\hline
\end{tabular}

The displacement curve is shown in figure 8, in which the blue curve is the displacement in $\mathrm{X}$ direction of wedge, the light yellow curve is the displacement in $\mathrm{Z}$ direction of wedge, and the brown curve is the displacement in Y direction. The results indicate that the displacement in $\mathrm{X}, \mathrm{Y}$ and $\mathrm{Z}$ directions changes during the movement of wedge, and the overall trend is that the displacement increases gradually, first slowly and then steeply, and finally remains unchanged. In the first three seconds, the displacement curve of the wedge increases slowly, the Z-direction displacement curve increases the most, reaching $20 \mathrm{~m}$, and the Y-direction displacement is almost unchanged; in the next four seconds, the displacement curve is similar to the parabola, and the displacement increases continuously.

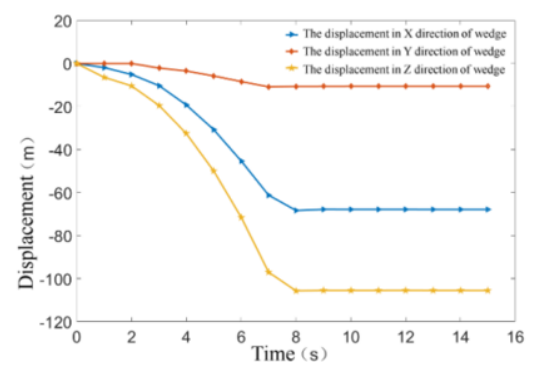

Figure 9. Displacement curve of the wedge.

The displacement data in three directions are imported into Matlab to realize the fitting of wedge motion trajectory and the results are shown in figure 9. The wedge moves slowly downward in the initial stage, and does not completely separate from the slope and thus the trajectory is relatively gentle. When the downward movement reaches $20 \mathrm{~m}$, the wedge separates from the slope and makes a motion similar to that of a free falling body. At this moment, the trajectory is rather steep and almost linear until the stop of the wedge, which is shown in figure 10 .

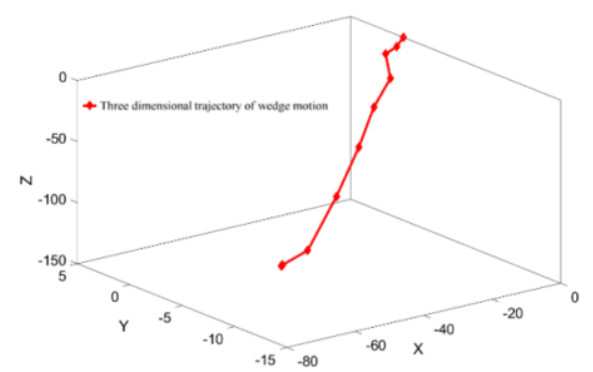

Figure 10. Three dimensional trajectory of wedge motion. 


\section{Conclusion}

This paper investigated the instability mode and movement characteristics of the dangerous rock body in a residential area. The following conclusions can be drawn:

(1) The wedge sliding instability mode is likely to occur when the dangerous rock body is cut by two groups of structural faces.

(2) The parameters of shear strength of the wedge in the study area are $\mathrm{C}=5 \mathrm{kPa}$ and $\varphi=23^{\circ}$, and the contact friction coefficient between wedge and rock mass is calculated for wedge dynamics analysis.

(3) Numerical results show that the track characteristics of wedge after instability is firstly slow and then becomes steep, and finally stays at the retaining wall. The lateral offset distance of $10 \mathrm{~m}$ is generated during the movement, which is consistent with the actual wedge motion characteristics.

\section{Acknowledgments}

This work is funded by the science and technology planning project of Guangdong Provincial Department of Housing and Urban-Rural Development with grant No. 2020K5-144658 and the science and technology planning project of Guangzhou Construction Group Co., Ltd with grant No. BH20210316448 and No. BH20210315403, which are sincerely appreciated.

\section{Reference}

[1] Chen HK, Wang R, Tang HM. A review of the research status and trend of dangerous rocks. Journal of Chongqing Jiaotong University. 2003 Sept; 22(3): 18-22. (in Chinese)

[2] Aref MO, AL-JABALI Abdo S, et al. Causes of rockfalls in Al-Huwayshah area, Yemen Global Geology. 2009 May; 12(1): 5-12.

[3] Fu XD and Deng JH. Qualitative and quantitative analysis of wedge stability. China Academic Journal Electronic Publishing House; 2009 Aug; (4): 7-10. (in Chinese)

[4] Hu HT. Collapse and rockfall. China Railway Publishing House; 1989. (in Chinese)

[5] Liu WH. Study on stability, movement characteristics and countermeasures of potential unstable rock mass in high-steep slope. Chengdu University of Technology; 2008 May. (in Chinese)

[6] Ye ZR. Numerical simulation of formation and evolution process of Wangxia Rock Mass and Wangxia and rockfall trajectory prediction. Jilin University; 2013 April. (in Chinese)

[7] Wang SJ, Xue SY. Dynamic analysis of wedge shape of rock mass slope. Scientia Geologica Sinica. 1992 Mar; (2): 177-182. (in Chinese)

[8] Tao LN, Zhang JH, He JD. The dynamic stability assessment of wedge blocks. Journal of Sichuan University (Engineering Science Edition). 2002 May; 34(3): 24-27. (in Chinese)

[9] Ma SZ, Jia HB, Zhang ZN, et al. Stability analysis of wedges of rock slopes based on 3D network simulation of structural surface. Chinese Journal of Geotechnical Engineering. 2018, Aug; 40(S2). (in Chinese) 